\title{
Emergent severe acute respiratory distress syndrome caused by adenovirus type 55 in immunocompetent adults in 2013: a prospective observational study
}

Bing Sun ${ }^{1,2+}$, Hangyong He ${ }^{1,2+}$, Zheng Wang ${ }^{1,2+}$, Jiuxin Qu ${ }^{2,3}$, Xuyan $\mathrm{Li}^{1,2}$, Chengjun Ban ${ }^{1,2}$, Jun Wan ${ }^{1,2}$, Bin Cao ${ }^{2,3}$, Zhaohui Tong ${ }^{1,2}$ and Chen Wang ${ }^{2,4^{*}}$

\begin{abstract}
Introduction: Since 2008, severe cases of emerging human adenovirus type 55 (HAdV-55) in immunocompetent adults have been reported sporadically in China. The clinical features and outcomes of the most critically ill patients with severe acute respiratory distress syndrome (ARDS) caused by HAdV-55 requiring invasive mechanical ventilation (IMV) and/or extracorporeal membrane oxygenation (ECMO) are lacking.

Methods: We conducted a prospective, single-center observational study of pneumonia with ARDS in immunocompetent adults admitted to our respiratory ICU. We prospectively collected and analyzed clinical, laboratory, radiological characteristics, sequential tests of viral load in respiratory tract and blood, treatments and outcomes.
\end{abstract}

Results: The results for a total of five consecutive patients with severe ARDS with confirmed HAdV-55 infection were included. All five patients were immunocompetent young men with a median age of 32 years. The mean time from onset to dyspnea was 5 days. Arterial blood gas analysis at ICU admission revealed profound hypoxia. Mean partial oxygen pressure/fraction of inspired oxygen was 58.1. Mean durations from onset to a single-lobe consolidation shown on chest X-rays (CXRs) and, from the first positive CXR to bilateral multilobar lung infiltrates, were 2 days and 4.8 days, respectively. The viral load was higher than $1 \times 10^{8}$ copies in three patients and was $1 \times 10^{4}$ in one patient. It was negative in the only patient who survived. The mean duration for noninvasive positive pressure ventilation (NPPV) failure and IMV failure were 30.8 hours and 6.2 days, respectively. Four patients received venovenous ECMO. Four (80\%) of the five patients died despite receiving appropriate respiratory support.

Conclusions: HAdV-55 may cause severe ARDS in immunocompetent young men. Persistent high fever, dyspnea and rapid progression to respiratory failure within 2 weeks, together with bilateral consolidations and infiltrates, are the most frequent clinical manifestations of HAdV-55-induced severe ARDS. Viral load monitoring may help predict disease severity and outcome. The NPPV and IMV failure rates were very high, but ECMO may still be the respiratory support therapy of choice.

Trial registration: Clinicaltrials.gov NCT01585922. Registered 20 April 2012

\footnotetext{
* Correspondence: cyh_birm@sina.com

${ }^{\dagger}$ Equal contributors

${ }^{2}$ Beijing Institute of Respiratory Medicine, Beijing Key Laboratory of Respiratory and Pulmonary Circulation, Capital Medical University, No. 8 Gongti Nanlu, Chaoyang district, Beijing, 100020, China

${ }^{4}$ Institute of Respiratory Medicine, Beijing Hospital, Ministry of Heath,

No. 1 Dahua Road, Dongcheng district, Beijing, 100730, China

Full list of author information is available at the end of the article
} 


\section{Introduction}

Human adenoviruses (HAdVs) are notorious pathogens in people with compromised immune function and a frequent cause of outbreaks of acute respiratory disease among young children. Life-threatening adenoviral pneumonia has previously been documented among military trainees, patients with AIDS and transplant recipients [1-5]. Human adenovirus type 55 (HAdV-55), which is emerging as a highly virulent pathogen for acute fatal adenoviral pneumonia among immunocompetent adults in China, has gained increasing attention [6]. HAdV-55 is a newly identified, emergent acute respiratory disease pathogen causing two recent outbreaks in China in 2006 [7] and in Singapore in 2005 [8]. In 2011, this pathogen apparently re-emerged in Beijing, China, causing several cases of severe community-acquired pneumonia [9]. This pathogen was fully characterized by whole-genome sequencing [10]. Comparative studies showed that the ability of HAdV to cause severe disease may relate to the serotypes of HAdVs. Severe adenoviral pneumonia induced by HAdV-55 has been reported to be more closely related to severe cases compared to other serotypes (HAdV-3, HAdV-7 and HAdV-14) [6].

Current knowledge of HAdV-55-induced severe acute respiratory distress syndrome (ARDS) requiring invasive mechanical ventilation and/or extracorporeal membrane oxygenation (ECMO) support in immunocompetent adults is derived from single case reports or relatively small, single-center series. As a result, little information is available on HAdV-55 pneumonia complicated with severe ARDS, the frequency of which is expected to increase in the coming years. Here we describe the clinical features and outcomes of five prospective cases of HAdV-55 pneumonia complicated with severe ARDS in immunocompetent adults in our ICU.

\section{Material and methods Study population}

Beginning in May 2012, a randomized trial of noninvasive positive pressure ventilation (NPPV) in ARDS patients was carried out in our center (ClinicalTrials.gov ID: NCT01585922). From May 2012 to April 2014, all adult patients with ARDS caused by pneumonia who were admitted to the respiratory ICU of Beijing Chao-Yang Hospital were prospectively enrolled. Severe ARDS was diagnosed according to the Berlin definition: (1) developing within 1 week of a known clinical insult or new or worsening respiratory symptoms; (2) bilateral opacities not fully explained by effusions, lobar and/or lung collapse, or nodules; (3) respiratory failure not fully explained by cardiac failure or fluid overload; (4) partial oxygen pressure/ fraction of inspired oxygen $\left(\mathrm{PaO}_{2} / \mathrm{FiO}_{2}\right) \leq 100 \mathrm{mmHg}$ with positive end-expiratory pressure (PEEP) $\geq 5 \mathrm{cmH}_{2} \mathrm{O}$; and (5) a chest radiograph with three or four quadrants with opacities. Patients with HAdV-55 infection and severe ARDS who failed conventional NPPV and invasive mechanical ventilation (IMV) were included in the analysis. This study was approved by the Institutional Review Board of Beijing Chao-Yang Hospital (LLKYPJ2012031). Data were analyzed anonymously. Each patient gave written informed consent for their data to be used for research and publication.

\section{Clinical data collection}

Clinical information collected by investigators with a standardized data form included the following: demographic characteristics (age and sex), comorbidities, clinical symptoms (fever, cough, sputum, dyspnea, chest pain, rash, nausea, vomiting, abdominal pain, diarrhea and headache), signs (body temperature, heart rate, respiratory frequency, blood pressure and crackles in the lungs), laboratory tests (whole-blood cell count and blood chemistry) and microbiological findings and images of the lung (chest X-ray (CXR) and computed tomography). Concomitant medications, respiratory support, complications and outcomes were also recorded.

\section{Microbiological tests}

Patients' specimens, including sputum, whole blood and serum samples, were collected upon admission and during hospitalization. Microbiological tests were performed at the Department of Infectious Disease and Clinical Microbiology in our center, and the detection methods used were described in our previous report [6]. Common viruses causing respiratory illness were screened using a kit with 15 different viral assays. Serum samples were used for Mycoplasma pneumoniae, Chlamydia pneumoniae and Legionella pneumophila antibodies. All patients had their HAdV-55 infection confirmed by RT-PCR assay. Partial sequences of the hexon gene were analyzed to type the phylogeny of HAdV-55 strains. The adenoviral load was also performed on both respiratory specimens and blood by multiplex RT-PCR assay.

\section{Criteria for human adenoviral pneumonia}

Viral pneumonia was diagnosed based on the presence of HAdV detected in sputum or throat swab samples by molecular methods.

\section{Statistical analysis}

Continuous variables were summarized as mean \pm standard deviation (SD) or median (interquartile range).

\section{Results}

During the study period, a total of eight patients diagnosed with HAdV infection and respiratory failure were admitted to our ICU, and seven of them received a diagnosis of ARDS. Five consecutive patients with severe 
Table 1 Demographic, clinical characteristics and laboratory values for immunocompetent adults with human adenovirus type 55 on the first day of admission ${ }^{\text {a }}$

\begin{tabular}{|c|c|c|c|c|c|c|c|c|c|c|c|c|c|c|c|}
\hline Patient & $\begin{array}{l}\text { Length of } \\
\text { onset to } \\
\text { dyspnea } \\
\text { (days) }\end{array}$ & $\begin{array}{l}\text { Length of } \\
\text { onset to ICU } \\
\text { admission } \\
\text { (days) }\end{array}$ & $\begin{array}{l}\text { Length of } \\
\text { NPPV } \\
\text { (hours) }\end{array}$ & $\begin{array}{l}\text { Length of IMV } \\
\text { before ECMO } \\
\text { (days) }\end{array}$ & $\begin{array}{l}\text { Length of ICU } \\
\text { stay (days) }\end{array}$ & $\begin{array}{l}\text { Length of hospital } \\
\text { stay (days) }\end{array}$ & $\begin{array}{l}\mathrm{T}_{\max } \\
\left({ }^{\circ} \mathrm{C}\right)\end{array}$ & $\mathrm{P} / \mathrm{F}$ & $\begin{array}{l}\text { Breathing rate } \\
\text { (breaths } / \mathrm{min} \text { ) }\end{array}$ & $\begin{array}{l}\text { WBC } \\
\left({ }^{*} 10^{9} / \mathrm{L}\right)\end{array}$ & $\begin{array}{l}\text { AST } \\
(U / L)\end{array}$ & $\begin{array}{l}\text { Creatinine } \\
(\mu \mathrm{mol} / \mathrm{L})\end{array}$ & $\begin{array}{l}\text { CK } \\
\text { (U/L) }\end{array}$ & $\begin{array}{l}\text { LDH } \\
(\mathrm{U} / \mathrm{L})\end{array}$ & $\begin{array}{l}\text { HBDH } \\
\text { (U/L) }\end{array}$ \\
\hline 1 & 1 & 11 & 48 & 6 & 4 & 7 & 39 & 61.6 & 38 & 10 & 137 & 139.6 & 132 & 1345 & 845 \\
\hline 2 & 10 & 11 & 24 & 4 & 5 & 9 & 39.5 & 62.5 & 40 & 5.17 & 190 & 78.5 & 1,653 & 1,666 & 953 \\
\hline 3 & 8 & 10 & 36 & 6 & 20 & 20 & 39.4 & 60.9 & 40 & 1.83 & 264 & 75.6 & 4,892 & 1,313 & 751 \\
\hline 4 & 2 & 8 & 22 & 2 & 19 & 24 & 40 & 49 & 52 & 2.1 & 213 & 70.2 & 2,586 & 1,577 & 1,079 \\
\hline 5 & 4 & 8 & 24 & 13 & 16 & 16 & 39.6 & 56.5 & 45 & 4.69 & 168 & 85.5 & 89 & 1,363 & 938 \\
\hline $\begin{array}{l}\text { Mean } \\
( \pm \text { SD })\end{array}$ & $5(3.9)$ & $9.6(1.5)$ & $30.8(11.1)$ & $6.2(3.7)$ & $12.8(7.7)$ & $15.2(7.2)$ & $\begin{array}{l}39.5 \\
(0.4)\end{array}$ & $\begin{array}{l}58.1 \\
(5.6)\end{array}$ & $43(6)$ & $\begin{array}{l}4.758 \\
(3.3)\end{array}$ & $\begin{array}{l}194.4 \\
(48.0)\end{array}$ & $\begin{array}{l}89.88 \\
(28.3)\end{array}$ & $\begin{array}{l}1,870.4 \\
(1,992.8)\end{array}$ & $\begin{array}{l}1,452.8 \\
(158.2)\end{array}$ & $\begin{array}{l}913.2 \\
(123.1)\end{array}$ \\
\hline
\end{tabular}

${ }^{\mathrm{a} A S T}$, Aspartate aminotransferase (normal range $=10$ to $42 \mathrm{U} / \mathrm{L}$ ); $\mathrm{CK}$, Creatine phosphokinase (normal range $=38$ to $174 \mathrm{U} / \mathrm{L}$ ); ECMO, Extracorporeal membrane oxygenation; $\mathrm{HBDH}$, Hydroxybutyrate dehydrogenase (normal range $=72$ to $182 \mathrm{U} / \mathrm{L}$ ); IMV, Invasive mechanical ventilation; LDH, Lactate dehydrogenase (normal range $=85$ to $250 \mathrm{U} / \mathrm{L}$ ); NPPV, Noninvasive positive pressure ventilation; P/F: Partial oxygen pressure/fraction of inspired oxygen; $T_{\max }$, Maximum temperature; WBC, White blood cell count (normal range $=4.00$ to $10.00^{*} 10^{9} / \mathrm{L}$ ). 
ARDS with confirmed HAdV-55 infection were admitted to our ICU between April and July 2013. They were included in the analysis. The other two patients had mild ARDS and were infected with other types of HAdVs.

\section{Demographics}

All five patients were immunocompetent young men with a median age of 32 years (range, 28 to 40 years). All of the patients shared a B blood type and came from the same city: Baoding city, Hebei province, northern China. All patients had no exposure to farm animals, corn or hay. Patient 3 had tuberculosis pleuritis and received antituberculosis therapy at ICU admission. His blood tests, including the T-SPOT tuberculosis assay (Oxford Immunotec, Marlborough, MA, USA) and antibody of Mycobacterium tuberculosis, were negative.

\section{Clinical characteristics}

Flulike symptoms, such as fever, cough and little sputum, were commonly observed at the onset of illness. All patients presented with a high fever, with a mean body temperature of $39.5^{\circ} \mathrm{C}$ (range, $39.0^{\circ} \mathrm{C}$ to $40.0^{\circ} \mathrm{C}$ ), which persisted for 8 days (range, 6 to 11 days). Productive cough was observed in two patients. Dull substernal chest pain and rash were also observed in two patients. All patients had dyspnea. The mean time from onset to dyspnea was 5 days (range, 1 to 10 days). After the onset of dyspnea, patients usually progressed to respiratory failure or hypoxemia. The mean time from onset to ICU admission was 9.6 days (range, 8 to 11 days) (Table 1 ).

All patients had tachypnea when admitted to the ICU, with a mean rate of 43 breaths per minute (range $=38$ to 52). Arterial blood gas analysis at ICU admission revealed profound hypoxia, with a mean $\mathrm{PaO}_{2} / \mathrm{FiO}_{2}$ of 58.1 (range $=49$ to 62.5 ). White blood cell counts were low or in the normal range. All patients had elevated serum aspartate aminotransferase (AST), lactate dehydrogenase (LDH) and hydroxybutyrate dehydrogenase (HBDH) (Table 1). At admission, all patients' levels of immunoglobulin (serum immunoglobulins $\mathrm{G}$ and $\mathrm{M}$ ) and components $\mathrm{C} 3$ and $\mathrm{C} 4$ were in the normal range.
Four patients had lower than normal T-cell subset counts (Table 2).

\section{Radiographic features}

CXRs revealed multiple bilateral lobar or segment consolidation in the lungs of all five patients, and radiographic lesions progressed rapidly after ICU admission (Figure 1). Three patients were examined by highresolution computed tomography (HRCT). Unilateral or bilateral consolidations and infiltrates were found on HRCT scans of all three of these patients. Consolidations within a single lobe or several lobes with a clear border and air bronchogram were the most common findings on HRCT scans. Nodules, patches, pleural effusion, abscess and a cavity were also seen visualized by HRCT (Figure 2). The mean duration from onset to a single-lobe consolidation on CXRs was 2 days (range $=1$ to 5 days). The mean duration from the first positive CXR to bilaterally multilobar lung infiltrates was 4.8 days (range $=4$ to 7 days).

\section{Detection of adenoviruses by RT-PCR}

All patients had HAdV-55 viremia. In four of the five patients, it was first detected in endotracheal aspirate (ETA) samples. The time between initial ETA sample collection of adenoviruses and positive results for HAdV-55 nucleic acid in the blood was 1 to 10 days (Table 3). Virus DNA copies in ETAs were determined for all patients during their ICU stay. The viral load was higher than $1 \times 10^{8}$ copies in three patients and $1 \times 10^{4}$ in one patient. The viral load became negative in the only patient who survived. In the four patients who did not survive, DNA copies did not decrease, even with antiviral therapy (Figure 3).

\section{Respiratory support}

Oxygenation was not maintained with conventional NPPV or IMV support in any of the patients. The mean duration until NPPV failure was 30.8 hours (range $=22$ to 48 hours), and the mean time until IMV failure was 6.2 days (range 2 = to 13 days) (Table 1 ). Four patients received venovenous ECMO to maintain oxygen saturation, and one patient refused ECMO support and received

Table 2 Humoral immunity and cell-mediated immunity on the immunocompetent adult infection with human adenovirus type $55^{\mathrm{a}}$

\begin{tabular}{llllllllll}
\hline Patient & Blood type & T cells $(\mathbf{n} / \mathbf{m l})$ & T4 cells $(\mathbf{n} / \mathbf{m l})$ & T8-cells $(\boldsymbol{n} / \mathbf{m l})$ & $\mathbf{l g G}(\mathbf{m g} / \mathbf{d l})$ & $\mathbf{l g A}(\mathbf{m g} / \mathbf{d l})$ & $\mathbf{l g M}(\mathbf{m g} / \mathbf{d l})$ & $\mathbf{C 3}(\mathbf{m g} / \mathbf{d l})$ & $\mathbf{C 4}(\mathbf{m g} / \mathbf{d l})$ \\
\hline Reference & & $(770$ to 2,040$)$ & $(410$ to 1,120$)$ & $(240$ to 880$)$ & $(751$ to 1,560$)$ & $(82$ to 453$)$ & $(46$ to 304$)$ & (79 to 152) & $(12$ to 36) \\
1 & B & 317 & 200 & 107 & 858 & 142 & 163 & 102 & 20.4 \\
2 & B & NA & NA & NA & NA & NA & NA & NA & NA \\
3 & B & 599 & 347 & 225 & 1260 & 136 & 64.2 & 86.8 & 26.4 \\
4 & B & 955 & 441 & 477 & 1640 & 110 & 92.3 & 38.7 & 13.1 \\
5 & B & 599 & 347 & 225 & 1260 & 136 & 64.2 & 86.8 & 26.4 \\
\hline
\end{tabular}

Ig, Immunoglobulin; NA, Not available; T cells, CD3-positive cells; T4 cells, Both CD3- and CD4-positive cells; T8 cells, Both CD3- and CD8-positive cells. 


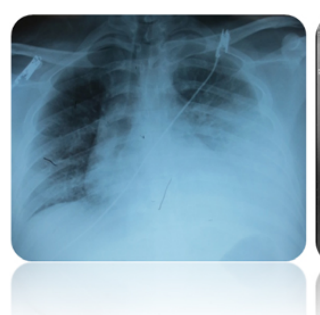

Day -3 DNA COPY: Not Available

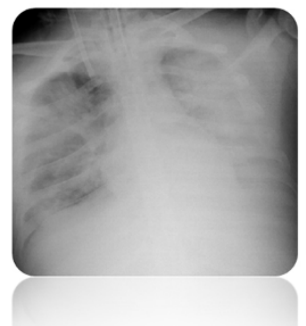

Day 13

ETA DNA: $6.90 * 10^{4}$

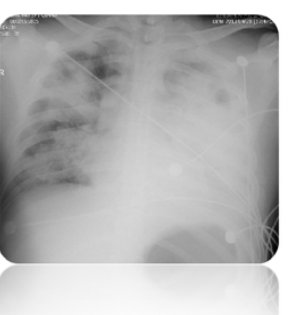

Day 1

ETA DNA: $2.40^{*} 10^{8}$

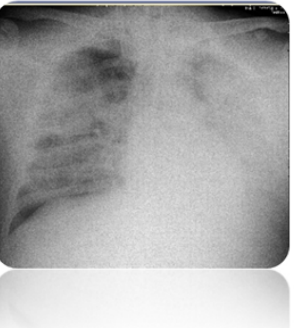

Day 15

ETA DNA: $3.00 * 10^{4}$

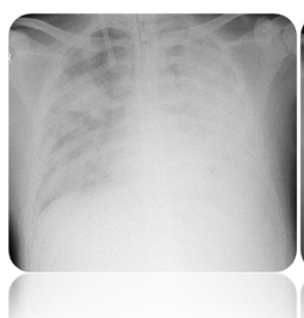

Day 3

ETA DNA: $1.26 * 10^{7}$

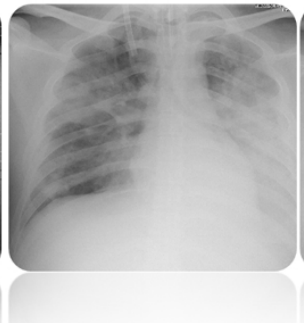

Day 17

ETA DNA: $9.30 * 10^{3}$
Day 7

ETA DNA: $1.29 * 10^{5}$
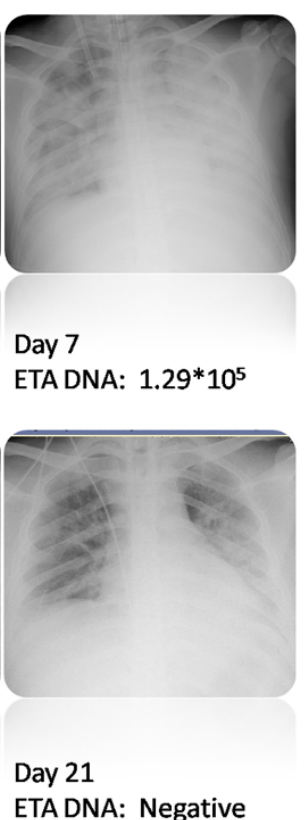

Figure 1 Radiographic findings and their relationship to viral load monitoring in patient 4. (Picture 1) Radiographs show widespread bilateral interstitial infiltrates at the onset of the disease. (Picture 2) The patient's condition rapidly deteriorated within 3 days, and mechanical ventilation was required. (Picture 3) The patient's adenoviral infection progressed, so supplementary oxygen was given on day 3 of admission. (Picture 4-8) Radiographs show gradual recovery with supportive therapy. Also shown are the trends of viral load detected with endotracheal aspirates (ETAs) and their relationship to radiological changes.

high-frequency oscillatory ventilation instead. Table 4 gives the oxygenation data of patients before and after venovenous ECMO support.

\section{Antimicrobiological therapy and outcome}

All patients received antiviral therapy, including acyclovir (10 mg/kg, every 8 hours, intravenous drip), ganciclovir (5 mg/kg, every 12 hours, intravenous drip) and ribavirin (250 mg, twice daily, intravenous drip). Considering that bacterial coinfection may combine with a severe viral infection, broad-spectrum intravenous antibiotics were given to all patients. Tests for bacterial pathogens were negative for only one patient (Table 3 ). Four (80\%) of the five patients died. Among the four patients receiving venovenous ECMO, only one patient survived. The other four patients died due to ARDS, Aspergillus fumigatus coinfection, septic shock and catheter-related bloodstream infection due to Acinetobacter baumannii, respectively.
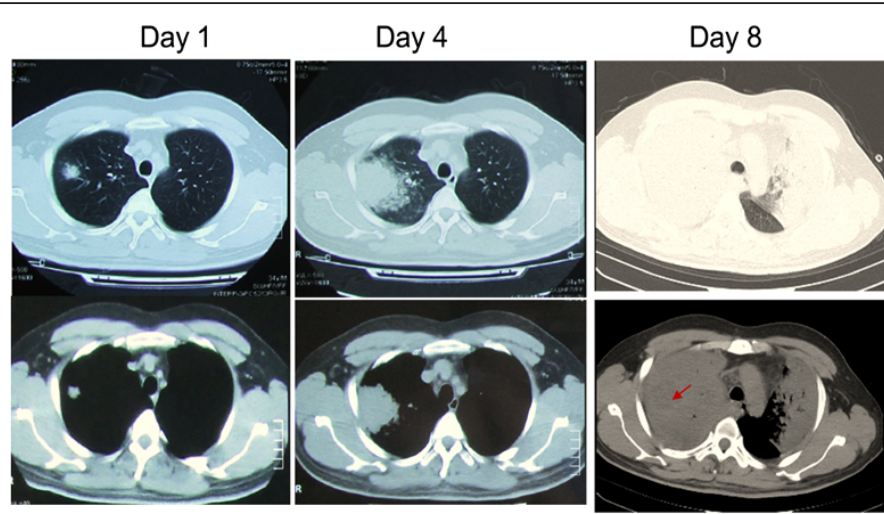

Day 23

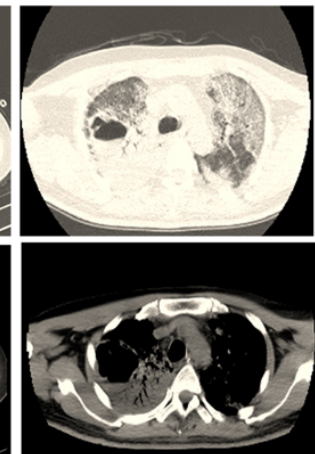

Figure 2 Dynamic changes on computed tomography scans for human adenovirus type $\mathbf{5 5}$ pneumonia in patient $\mathbf{3}$. Chest computed tomography scans taken on day 1 show a nodular shadow in the right upper lobe. The nodular shadow expanded dramatically within 3 days and was surrounded by ground-glass opacity on day 4. The lesion was diffuse in both lung fields on day 8 . A cavity was observed on day 23 , and the mediastinum window shows the formation of pulmonary abscess in the upper right lobe (red arrow). The lung abscess tested negative for Legionella, Staphylococcus and tuberculosis. 
Table 3 Common respiratory pathogen coinfection with human adenovirus type 55 and patients' clinical outcomes ${ }^{a}$

\begin{tabular}{|c|c|c|c|c|c|c|c|c|}
\hline Patient & $\begin{array}{l}\text { Initial detection } \\
\text { method }\end{array}$ & $\begin{array}{l}\text { Days of positive } \\
\text { HAdV in blood tests }\end{array}$ & $\begin{array}{l}\text { Highest PCT } \\
\text { level }(\mathrm{ng} / \mathrm{ml})\end{array}$ & Bacteria & Fungus & G-test $(\mathrm{pg} / \mathrm{ml})$ & Outcome & $\begin{array}{l}\text { Cause } \\
\text { of death }\end{array}$ \\
\hline 1 & Sputum & 2 & 5.66 & Negative & Negative & $<10$ & Death & ARDS \\
\hline 2 & Throat swab & 1 & 4.67 & Negative & $\begin{array}{l}\text { Aspergillus } \\
\text { fumigatus }\end{array}$ & $<10$ & Death & ARDS, IPA \\
\hline 3 & Sputum & 2 & 30.14 & $\begin{array}{l}\text { Acinetobacter } \\
\text { baumannii, Burkholderia } \\
\text { cepacia, Staphylococcus }\end{array}$ & Pneumocystis & 164.7 & Death & $\begin{array}{l}\text { Septic shock, } \\
\text { MODS }\end{array}$ \\
\hline 4 & Sputum & 10 & 1.58 & $\begin{array}{l}\text { Acinetobacter } \\
\text { baumannii }\end{array}$ & Negative & $<10$ & Survival & - \\
\hline 5 & Sputum & 2 & 0.48 & $\begin{array}{l}\text { Acinetobacter } \\
\text { baumannii }\end{array}$ & Negative & 256.1 & Death & CRBSI \\
\hline
\end{tabular}

${ }^{\mathrm{a}} \mathrm{ARDS}$, Acute respiratory distress syndrome; CRBSI, Catheter-related bloodstream infection; 1,3-beta-D-glucan, G-test (reference <20 pg/ml); HAdV, Human adenovirus; IPA, Invasive pulmonary aspergillosis; MODS, Multiple organ dysfunction syndrome; PCT, Procalcitonin (reference $<0.05 \mathrm{ng} / \mathrm{ml}$ ).

\section{Discussion}

To the best of our knowledge, this is the first cohort observational study on the clinical characteristics of patients with severe ARDS caused by emergent HAdV-55 infection and also the first on the evaluation of a viral load test for monitoring the reaction to therapy and for prediction of patient outcome. The following are the main findings of this study. (1) HAdV-55 may cause severe ARDS in immunocompetent young men with blood type B. All of our patients were from the same city of Hebei province, northern China. (2) Persistent high fever, dyspnea and rapid progression to respiratory failure within 2 weeks, together with bilateral consolidations and infiltrates at the same time, are the most frequent clinical manifestations of severe HAdV-55induced ARDS. (3) Viral load monitoring may help predict disease severity and patient outcome. (4) The NPPV and IMV failure rates were very high, and ECMO may be the last support method for this group of patients. (5) HAdV55 -induced severe ARDS has a very high mortality rate (80\%) despite appropriate respiratory support.

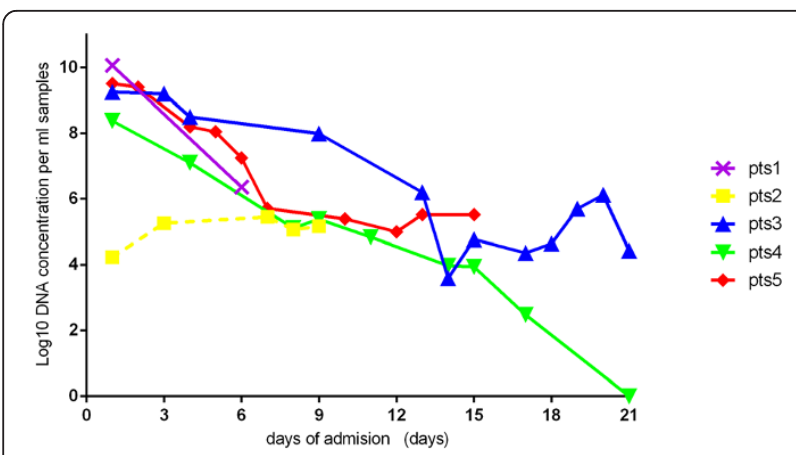

Figure 3 Changes in human adenovirus type 55 concentration measured in endotracheal aspirates from all five acute respiratory distress syndrome patients. Patient 4 , whose viral DNA copies in ETA became negative, was the only patient who survived.
Sporadic severe adenoviral infection in healthy adults has historically been described for serotype 4 [11], serotype $7[4,12]$ and, more recently, serotype 14 in the general population and in military trainees $[13,14]$. HAdV-55 was first completely characterized in Shaanxi, China [7] and then reemerged in Hebei, a province close to Beijing, where it caused several cases of acute respiratory disease [9]. It was presumed that HAdV-55 was a recombinant form of the B2 species of HAdV-14 and HAdV-11 [7,15] due to its sharing a hexon gene with the HAdV-11 and HAdV-14 chassis [16]. The results of our study show that HAdV-55, as an emerging pathogen among immunocompetent adults, may cause severe ARDS.

The prevalence of severe fatal adenoviral pneumonia induced by HAdV-55 in our study is somewhat similar to that described by Cao and colleagues [6]. All cases of reported HAdV-55 in our study were from the same city: Baoding, Hebei province, northern China. They occurred between April and July 2013, just partly overlapping or following the influenza epidemic. The patients with severe disease also came from the same region and were treated during a similar time period, which suggests that HAdV-55 may be an important viral pathogen derived from this region.

Our study results suggest that the following may be clinical features of ARDS caused by HAdV-55: persistent high fever, rapid progression of dyspnea, need for mechanical ventilation support, elevated AST level and rapid progression from unilateral infiltrates to bilateral consolidations. These clinical features are highly similar to those of ARDS caused by other types of HAdV described in previous reports $[6,9]$.

Recent studies have shown that the immune system plays a crucial role in the clearance of HAdV viremia and survival of the host [17]. Chen et al. reported that, in the acute phase of HAdV-55 infection, patients with severe disease may have high levels of dendritic cells and Th17 cells [18]. In our study, the only patient who 
Table 4 Oxygenation response to venovenous extracorporeal membrane oxygenation support ${ }^{\mathrm{a}}$

Patient Conventional ventilation settings pre-ECMO Pre-ECMO arterial blood gas analysis $\quad$ Mechanical ventilation settings post-ECMO Post-ECMO arterial blood gas analysis

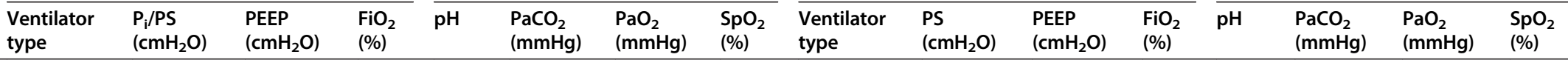

Patient 1: ECMO manufacturer/model (4,150 rpm; MAQUET (Wayne, NJ, USA)), $5.2 \mathrm{~L} / \mathrm{min}, 6.8 \mathrm{~L} / \mathrm{min}$, total of 8 days on ECMO
PSV
12
20
$7.229 \quad 62.3$
76.7
65 PA/C
10
20
0.3

$\begin{array}{lll}7.406 & 37.5 & 74.7\end{array}$
93
$\mathrm{PA} / \mathrm{C}$
18
10
$\begin{array}{lll}0.8 & 7.267 \quad 81\end{array}$
$76.394 \quad$ No

Patient 3: ECMO manufacturer/model (3,950 rpm; MAQUET (Wayne, NJ, USA)), 5.0 L/min, 5.0 L/min, total of 6 days on ECMO
$\mathrm{PA} / \mathrm{C}$
12
20
$7.25 \quad 66.4$
75.4
$90 \quad \mathrm{PA} / \mathrm{C}$
10
18
0.4
$\begin{array}{lll}7.517 & 41.2 & 71.5\end{array}$
96

Patient 4: ECMO manufacturer/model (3,740 rpm; MAQUET (Wayne, NJ, USA)), $4.38 \mathrm{~L} / \mathrm{min}, 4.0 \mathrm{~L} / \mathrm{min}$, total of 2 days on ECMO
SIMV
24
10
$7.44 \quad 38$
44
$76 \quad \mathrm{PA} / \mathrm{C}$
10

14

$\begin{array}{llll}0.35 & 7.441 & 37.5 & 89.6\end{array}$

96.8

Patient 5: ECMO manufacturer/model (3,340 rpm; MAQUET (Wayne, NJ, USA)), $4.9 \mathrm{~L} / \mathrm{min}, 4.5 \mathrm{~L} / \mathrm{min}$, total of 13 days on ECMO
PA/C
$7.347 \quad 74.2$
$80.2 \quad 83 \quad \mathrm{PA} / \mathrm{C}$
12
14
$\begin{array}{lll}0.3 & 7.485 \quad 40.8\end{array}$
103
96

${ }^{\mathrm{a}} \mathrm{ECMO}$, Extracorporeal membrane oxygenation; $\mathrm{FiO}_{2}$, Fraction of inspired oxygen; $\mathrm{HFOV}$, High-frequency oscillatory ventilation; $\mathrm{PA} / \mathrm{C}$, Pressure assist/control; PaCO ${ }_{2}$, Partial pressure of carbon dioxide; PaO ${ }_{2}$, Partial pressure of oxygen; $\mathrm{P}_{\text {aw, }}$ Airway pressure; PEEP, Positive end-expiratory pressure; $\mathrm{P}_{\mathrm{i}}$, Initial pressure; PS, Sustained pressure; PSV, Pressure support ventilation; SIMV, Synchronized intermittent mechanical ventilation; SpO ${ }_{2}$, Peripheral capillary oxygen saturation; rpm, rounds per minute. The two liters per minute means the range of blood flow provided at the pump rounds level of ECMO. 
recovered from severe infection had higher T-cell counts. Three of the five patients had relatively low T-cell counts when admitted. Our results suggest that these three patients may have been relatively immunocompromised and that a lower $\mathrm{T}$-cell count may be a risk factor for HAdV-55 infection in young adults.

HAdV-55 DNA was previously reported in $41.2 \%$ of patients with severe infection [18]. In our study, HAdV55 DNA was detected and monitored in all patients with severe ARDS. The initial, and trend of, viral load that presented as HAdV-55 DNA copies in the respiratory tract samples and blood may suggest the severity of infection and may predict both the reaction to therapy and patient outcome.

The use of mechanical ventilation and ECMO in patients with ARDS caused by HAdV-55 has not been detailed in previous studies. In our cohort, we found that severe HAdV-55 infection could cause a rapid progression of respiratory failure, with a very high failure rate for NPPV and IMV. This failure rate may be a result of the large area of consolidation that induced a severe shunt in the lung, which may lead to lack of response to positive pressure ventilation. For patients with severe ARDS, ECMO should be considered a better choice for oxygenation.

Our study has limitations. It is an observational study with no comparison group, so the difference between the severe and modest infections could not be clarified in terms of immune status, clinical features, radiological findings, viral load and treatment effects on respiratory support and antiviral therapy. Sequential dynamic analysis is needed to determine the relationship between HAdV-55 viremia and treatment response.

\section{Conclusions}

Our data provide new insight into the clinical features of HAdV-55 infection in patients with severe ARDS. HAdV-55 may cause severe ARDS in immunocompetent young men. Persistent high fever, dyspnea and rapid progression to respiratory failure within 2 weeks, together with bilateral consolidations and infiltrates during the same period, are the most frequent clinical manifestations of severe HAdV-55-induced ARDS. Viral load monitoring may help predict disease severity and patient outcome. NPPV and IMV failure rates were very high, and thus ECMO may be a better choice of respiratory support in this group of patients. HAdV-55-induced severe ARDS has a very high mortality rate $(80 \%)$ despite appropriate respiratory support.

\section{Key messages}

- HAdV-55 infection may be a cause of severe ARDS in immunocompetent young male adults.
- Persistent high fever, dyspnea, rapid progression to respiratory failure within 2 weeks, together with bilateral consolidations and infiltrates during the same period, are the most frequent clinical manifestations of severe HAdV-55-induced ARDS.

- Viral load monitoring may be helpful in predicting patients' disease severity and outcome.

- NPPV and IMV failure rates were very high, and thus ECMO may be a better choice for respiratory support in this group of patients.

- HAdV-55-induced severe ARDS has a very high mortality rate of $80 \%$ despite appropriate respiratory support.

\section{Abbreviations}

ARDS: Acute respiratory distress syndrome; CXR: Chest X-ray; ECMO: Extracorporeal membrane oxygenation; ETA: Endotracheal aspirate; HAdV-55: Human adenovirus type 55; IMV: Invasive mechanical ventilation; NPPV: Noninvasive positive pressure ventilation; PEEP: Positive end-expiratory pressure.

\section{Competing interests}

The authors declare that they have no competing interests.

\section{Authors' contributions}

CW takes full responsibility for the integrity of the submission and publication and was involved in study design. BS, HH and ZW had full access to all the data in the study, take responsibility for the integrity of the data and the accuracy of the data analysis, and were responsible for data verification and analysis and the drafting of the manuscript. ZT takes responsibility for the acquisition of the data and the interpretation of the data analysis. JQ, CB, BC, JW and XL were responsible for the microbiological examination and data collection. All authors read and approved the final manuscript.

\section{Author details}

${ }^{1}$ Department of Respiratory and Critical Care Medicine, Beijing Chao-Yang Hospital, Capital Medical University, No. 8 Gongti Nanlu, Chaoyang district, Beijing, 100020, China. ${ }^{2}$ Beijing Institute of Respiratory Medicine, Beijing Key Laboratory of Respiratory and Pulmonary Circulation, Capital Medical University, No. 8 Gongti Nanlu, Chaoyang district, Beijing, 100020, China. ${ }^{3}$ Department of Infectious Diseases and Clinical Microbiology, Beijing Chao-Yang Hospital, Capital Medical University, No. 8 Gongti Nanlu, Chaoyang district, Beijing, 100020, China. Institute of Respiratory Medicine, Beijing Hospital, Ministry of Heath, No. 1 Dahua Road, Dongcheng district, Beijing, 100730, China.

Received: 19 May 2014 Accepted: 15 July 2014

Published: 12 August 2014

\section{References}

1. Hakim FA, Tleyjeh IM: Severe adenovirus pneumonia in immunocompetent adults: a case report and review of the literature. Eur J Clin Microbiol Infect Dis 2008, 27:153-158.

2. Bear OF, Shaefer LM, Kellen-Anderson LM, Parker SL, Schnurr DP, Gaydos JC: Civilian outbreak of adenovirus acute respiratory disease-South Dakota, 1997. JAMA 1998, 280:596.

3. Hwang SM, Park DE, Yang YI, Park SJ, Lee HK, Kim MJ, Chun BC: Outbreak of febrile respiratory illness caused by adenovirus at a South Korean military training facility: clinical and radiological characteristics of adenovirus pneumonia. Jpn J Infect Dis 2013, 66:359-365.

4. Dudding BA, Wagner SC, Zeller JA, Gmelich JT, French GR, Top FH Jr: Fatal pneumonia associated with adenovirus type 7 in three military trainees. N Engl J Med 1972, 286:1289-1292.

5. Klinger JR, Sanchez MP, Curtin LA, Durkin M, Matyas B: Multiple cases of life-threatening adenovirus pneumonia in a mental health care center. Am J Respir Crit Care Med 1998, 157:645-649. 
6. Cao B, Huang GH, Pu ZH, Qu JX, Yu XM, Zhu Z, Dong JP, Gao Y, Zhang YX, Li XH, Liu JH, Wang H, Xu Q, Li H, Xu W, Wang C: Emergence of community-acquired adenovirus type 55 as a cause of community-onset pneumonia. Chest 2014, 145:79-86.

7. Yang Z, Zhu Z, Tang L, Wang L, Tan X, Yu P, Zhang Y, Tian X, Wang J, Li D, Xu W: Genomic analyses of recombinant adenovirus type 11a in China. J Clin Microbiol 2009, 47:3082-3090.

8. Kajon AE, Dickson LM, Metzgar D, Houng HS, Lee V, Tan BH: Outbreak of febrile respiratory illness associated with adenovirus 11a infection in a Singapore military training camp. J Clin Microbiol 2010, 48:1438-1441.

9. Gu L, Liu Z, Li X, Qu J, Guan W, Liu Y, Song S, Yu X, Cao B: Severe community-acquired pneumonia caused by adenovirus type 11 in immunocompetent adults in Beijing. I Clin Virol 2012, 54:295-301.

10. Zhang Q, Seto D, Cao B, Zhao S, Wan C: Genome sequence of human adenovirus type 55 , a re-emergent acute respiratory disease pathogen in China. J Virol 2012, 86:12441-12442.

11. Levin S, Dietrich J, Guillory J: Fatal nonbacterial pneumonia associated with adenovirus type 4: occurrence in an adult. JAMA 1967, 201:975-977.

12. Low SY, Tan TT, Lee CH, Loo CM, Chew HC: Severe adenovirus pneumonia requiring extracorporeal membrane oxygenation support-serotype 7 revisited. Respir Med 2013, 107:1810-1813.

13. Lewis PF, Schmidt MA, Lu X, Erdman DD, Campbell M, Thomas A, Cieslak PR, Grenz LD, Tsaknardis L, Gleaves C, Kendall B, Gilbert D: A community-based outbreak of severe respiratory illness caused by human adenovirus serotype 14. J Infect Dis 2009, 199:1427-1434.

14. Tate JE, Bunning ML, Lott L, Lu X, Su J, Metzgar D, Brosch L, Panozzo CA Marconi VC, Faix DJ, Prill M, Johnson B, Erdman DD, Fonseca V, Anderson LJ, Widdowson MA: Outbreak of severe respiratory disease associated with emergent human adenovirus serotype 14 at a US Air Force training facility in 2007. J Infect Dis 2009, 199:1419-1426.

15. Walsh MP, Seto J, Jones MS, Chodosh J, Xu W, Seto D: Computational analysis identifies human adenovirus type 55 as a re-emergent acute respiratory disease pathogen. J Clin Microbiol 2010, 48:991-993.

16. Chmielewicz B, Benzler J, Pauli G, Krause G, Bergmann F, Schweiger B: Respiratory disease caused by a species $B 2$ adenovirus in a military camp in Turkey. J Med Virol 2005, 77:232-237.

17. Hendrickx R, Stichling N, Koelen J, Kuryk L, Lipiec A, Greber UF: Innate immunity to adenovirus. Hum Gene Ther 2014, 25:265-284.

18. Chen WW, Nie WM, Xu W, Xie YX, Tu B, Zhao P, Qin EQ, Zhang YH, Zhang X, Li WG, Zhou ZP, LV JY, Zhao M: Cross-sectional study of the relationship of peripheral blood cell profiles with severity of infection by adenovirus type 55. BMC Infect Dis 2014, 14:147.

doi:10.1186/s13054-014-0456-6

Cite this article as: Sun et al:: Emergent severe acute respiratory distress syndrome caused by adenovirus type 55 in immunocompetent adults in 2013: a prospective observational study. Critical Care 2014 18:456.

\section{Submit your next manuscript to BioMed Central and take full advantage of:}

- Convenient online submission

- Thorough peer review

- No space constraints or color figure charges

- Immediate publication on acceptance

- Inclusion in PubMed, CAS, Scopus and Google Scholar

- Research which is freely available for redistribution 